\title{
Lexico-grammatical Analysis of Native and Non- native Abstracts Based on Halliday's SFL Model
}

\author{
Massome Raeisi \\ Department of English, Shahreza Branch, Islamic Azad University, Shahreza, Iran \\ Hossein Vahid Dastjerdi \\ University of Isfahan, Isfahan, Iran; \\ Shahreza Branch, Islamic Azad University, Shahreza, Iran \\ Mina Raeisi \\ Department of English, Isfahan (Khorasgan) Branch, Islamic Azad University, Isfahan, Iran
}

\begin{abstract}
The present study attempts to qualitatively investigate lexico-grammatical properties of academic journal abstracts written by both native and non-native speakers in educational psychology, based on Halliday's systemic functional linguistic (SFL) Model. To this end, 30 (15 native and 15 non-native) abstracts were selected and downloaded from two international journals as the corpus of the study. In order to determine lexico-grammatical features of both groups, the frequencies of three variables i.e. lexical density, adjuncts, and transitivity were compared and contrasted. The results showed that no significant difference was seen between native and non-native abstracts in terms of lexical density $(59.72 \%$ and $59.91 \%$ respectively). Adjuncts were used more in the non-native abstracts than in native ones. Moreover, lexico-grammatical features of transitivity items (existential, verbal, behavioral, mental, material, and relational) in non-native abstracts were significantly more than the native ones. The findings of this study can be useful for EFL students as well as teachers to enhance the quality of their writings for presenting them in academic contexts and leading journals.
\end{abstract}

Index Terms - Halliday's SFL model, lexico-grammatical features, native and non-native abstracts

\section{INTRODUCTION}

Globalization is the newest issue that the world is moving toward. Obviously such fast-developing process needs having interaction and communication with people around the world. Not only translation makes the mentioned interaction possible, but also it is directly associated with the best quality of development in different areas. Academic research is growing up and its lexical features in the process of translation need to be more precise to be transferred for being compatible with lexical features of the native researchers. This work would be possible by applying Halliday's systemic functional linguistic (SFL) model to know more about the relationship between the semantic notions conveyed through lexical items.

Standards of the academic journals are usually in the light of native English language patterns. This issue would be more vital when non-native researchers carry out a research and submit it to a native journal. Therefore, those research conducted by non-natives will not have the criteria of being published in the native journals, if the author is not aware of the lexical patterns. Due to the existence of this problem in non-native translations as well as the problem of compatibility with the native texts, it seems necessary to shed more light on semantic aspects and lexico-grammatical patterns of native texts which include transitivity, adjunct and lexical density. Contradictions between lexicogrammatical patterns of native and non-native texts caused more significant differences between native and non-native research quality.

Systemic functional linguistic (SFL): According to Michel O'Donnell (2011) "SFL is an approach to language developed by M.A.K. Halliday and his followers during the 1960s in the United Kingdom, and later in Australia" (p. 1). Halliday's Systemic Functional Linguistics is from among the most outstanding and remarkable theories which is widely applicable in linguistics and literature.

Martin (1984) and Paltridge (2012) believed that a target-based, staged, and determined activity that the author or speaker tries to involve his/her culture and conditions in that can be a definition for genre. People have designed corpus for the aim of analysis, therefore they normally select texts to provide a sample of particular text-types, or genres, or a piece of spoken and/or written discourse (Stubbs, 2004).

Transitivity: According to Halliday and Matthiessen (2004) transitivity includes the processes, in the verbal group, the participants (human/non-human) who are participating in these processes, in the noun group, the circumstances in which the processes occur and the when, where, and how they take place, in the prepositional phrase and adverbial group. 
Lexical density: Based on Halliday (1994), lexical density measures the density of information in a text and analyzes the compaction of lexical items which arranged into the grammatical structure.

Adjunct: Almurashi (2016) maintained that adjunct is a subcategory of mood analysis which includes adjunct, subject and finite. In fact, adjunct is the structurally dispensable and optional part of a sentence, clause, or phrase that will not be able to change the meaning by removing from that sentence. Also, according to White (2000), the time, place, and the manner of the happenings are shown by adjuncts, as it is possible to be positive or negative to show different sides of a clause.

The research was established based on the theory of systemic functional linguistic (SFL). In fact, SFL is a particular method to linguistics who think of language as a social semiotic system, this system was enriched by Michael Halliday; this concept was taken from his professor, J. R. Firth. According to Martin (1997) "Functional linguistics are fundamentally concerned with showing how the organization of language to relate to its use" (p. 4).

According to Halliday (1994); Halliday and Matthiessen (2004); Halliday and Webster (2009),three main metafunctions can be considered in language in the theory of systemic functional linguistics. The mentioned metafunctions can be identified in any piece of language use including ideational, interpersonal and textual. The ideational metafunction comprises human's perception of the world and the relationship between the concepts and entities. The social role and potentials of language that were proven by the interpersonal metafunction. Finally, the factors that textual metafunction deals with are the arrangement and the emphasis on various parts and elements in utterances and clauses. Accordingly, based on Eggins (2004); Halliday (1994); Halliday and Matthiessen (2004); Martin, Matthiessen, and Painter (1997); Thompson (1996, 2004), there of the most important determinants determined the aforementioned metafunctions. They are field, tenor, and mode. Field is the first one which is parallel to the ideational metafunction, or the subject of content, or the notions and concepts that are the matter of discussions. The other name given to this term is "a discourse type". People's social ranks and relations, that is based on interpersonal metafunction, are categorized as the other factor which believe that they are involved in a linguistic exchange. Mode, the last factor, runs parallel to textual metafunction and pertains to the form and format of the text being produced and exchanged that written and spoken can be named as the simplest examples.

Lexical density, the most frequent lexical items, and keywords are three parts of lexical features' analysis. Based on Halliday (1994), information density of a text is measured by its lexical density. "according to how tightly the lexical items have been packed into the grammatical structure" (p. 76).

Process in SFL is the semantic phenomenon realized by verbs. The accompanying participants are specified in the light of the type of process (Halliday \& Matthiessen, 2004). Halliday and Matthiessen (2004) believe that "there are six main process types in English. The grammar of experience: process types in English. The processes of the outer experience in the world are referred to the material processes, while those denoting the inner experience, or the experience of consciousness, are referred to as mental processes. The processes expressing the theory and practice in language studies or relation between two fragments of experience are called relational processes. Verbal processes refer to those that are induced by inner experience and involve any type of saying or doing something with language.

As Halliday and Matthiessen (2004); Praxedes Filho (2004); Yuli and Yushan (2012) said, behavioral processes are what we see as the manifestation of the real feelings, experiences, and decisions like crying. Finally, the existential process type refers to verbs that accordingly all phenomena of all kinds are simply recognized to "be", or "exist". The point needs to be clarified that these are the main process types of most of languages."

It is worthwhile to add that Halliday's SFL model is general and can be used in a variety of the fields like education, translation, discourse analysis, history, sociology and children language development. Therefore, according to Halliday and Webster (2009) lots of research used SFL model in their works and interestingly attractive and enticing results and implications were found in the foregoing and the rest of the fields

SFL is a broad and widely-accepted approach to analyze language with respect to its functional meaning (Young \& Harrison, 2004). Therefore, its application is very far-reaching, effective, and productive (Banks, 2002).

Another similar study conducted by Almurashi (2016) entitled "An introduction to Halliday's systemic functional linguistics". It precisely explained the keywords of SFL and gave an applicable tradition, some instances for showing the value of applying SFL precisely, and also the positive points and gains of dealing with SFL as a communicative motivation in language learning. It obviously was a general topic in comparison with the present research.

In terms of the articles analyzed academic abstracts as the source of text analysis, Valipour, Aidinlu, and Asl (2016) have conducted a research entitled "Investigating lexico-grammaticality in academic abstracts and their full research papers from a diachronic perspective". Three disciplines, with one field as a subcategory in each discipline, were under concentration in this study. Besides, BNC general English was used as the reference corpus. The factors analyzed in both abstracts and full articles included lexical patterns, keywords and keenness value. According to the results of this study, in comparison with general English and particularly the use of specific lexical items, a wide variety of the probable lexical realizations were used differently.

Likewise, beside analyzing lexico-grammatical features of academic abstracts, Holtz (2011), analyzed full articles too, then he compared the mentioned properties to see the difference between these two text types in a broader linguistic context. In his corpus which was based on practices in corpus linguistics, he decided to compile and process texts in the field of computer science, linguistics, biology, and mechanical engineering. Interestingly, he found out there is a 
significant distinction between the abstracts and their research together with a clear domain specific variation. Although different methodologies were used in these two articles, both of them identified similar results.

Holtz (2011), performed a twofold methodology including deductive empirical analysis and an inductive empirical analysis to corroborate the outcomes of the deductive analysis, while Valipour et al. (2016) analyzed lexicogrammatical variations of the corpus synchronically, diachronically, and over time to conduct their research and then they used Word Smith Tools Software for the corpus analysis and then SPSS has been used.

The findings of another research carried out by Norouzi, Farahani, and Farahani (2012) entitled "Deverbal nominalizations across written-spoken dichotomy in the language of science" revealed that the mostly-used elements were the verbs in spoken modality and nominalizations in written. Besides, both verbs and deverbal nominalizations accounted as the most frequent material process types. (Verb categorization base and the other related nominalized editions employed their process typology from Halliday's systemic functional grammar framework.) Lower frequency of nominalizations proved the fact that from among the verbs, relational process types were assigned the second highest frequency.

Norouzi et al. (2012), focused on both written and spoken materials, but Rodriguez Arancón (2013) just focused on written materials and analyzed essays done by Universidad Nacional de Educacion a Distancia (UNED) students. This written corpus was just selected from the essays of L2 students in Business English course. Particular types of lexicogrammatical errors were the source analysis in the form of three macro-functions of SFL-based genre analysis. The chosen text of this corpus was analyzed in three different ways for transitivity, mood and theme. Each analysis corresponded to the exploration of field, tenor and mode. Results of this study have shown that if genre's forms of canonical could be controlled better, students can write more creatively and communicatively with less errors because they can view the text as a whole piece of language.

In a separate article, the spoken augural addresses of America's President were analyzed by Huen (2011). He selected political context of a presidential debate (President Barack Obama and Jeorge W. Bush) in a way that it was completely spoken, on the contrary of Rodriguez Arancen's article which analyzed lexico-grammatical aspects of a written text. In order to have a deep understanding of systemic functional linguistics, the unit of evaluation was clause (exactly in two levels of clauses including within the clause and beyond the clause) that was suitable for analyzing transitivity structure, clause-complex logical relations, the organization of functionally-significant text spans, and thematic progression. As Bush's text was used as the reference, Obama's lexico-grammatical analysis is in a way that one to two kind of transitivity structure with stable process type and participants were employed, small number of theme was used, a considerable and logical number of rhetorical structures were used that consequently shows that in terms of lexicogrammatical options, both of them had some likeness and dissimilarity.

In a research paper presented in a conference entitled "Lexical density and readability - a case study in English textbooks", it is found that although a common sense of lexical density exists, it is probable that the typical type of complexity in written language (Halliday, 1985) rise regularly with the text levels and their readability; as a result, there was not any significant relationship between them in reading comprehension texts. Another important point of this article mentioned by To, Fan, and Thomas (2013) is that on the contrary to the present research, that linguistic complexity of the texts in English textbooks was mostly pertained to its grammatical aspects, not lexical density.

Teich, Janich, and Holtz (2011) found that for distinguishing the tenor of discourse and its categorizations, social distance, and social role relationship, signs and indicators of which are modals, nominalizations, sentence length, vocabularies, type/token ratio, and grammatical complexity, abstracts and research articles were significantly different; that is, they used less modals than research articles. Also, with respect to SFL perspective on collocation, it is found that sign and its habitual contexts have a dependent relationship, however many other linguists choose collocation analysis by the use of large-scale corpus analysis (Gledhill, 2009).

Based on the results of two articles conducted by Henrique (2004) and Pedro Henrique Lima Praxedes Filho, a high level of spoken and written narrative's complexity was seen which were $87.61 \%$ and $94.14 \%$ for separate levels of complexity and $90.72 \%$ for mixed level complexity. Additionally, in order to gain the advanced level of lexicogrammatical complexity, using SFG was strongly recommended in this article.

The objectives of this research are:

1. To examine the significant differences between native and non-native abstracts in terms of transitivity (process types).

2. To examine the differences between native and non-native abstracts in terms of lexical density.

3. To analyze mood of abstracts and determine different types of adjuncts.

Publishing an article in a native journal with high IF is what every researcher seeks that needs following writing standards of English language. To obtain this object, providing a native translation plays a crucial role. The implication and result of this research can be finding a resort to recognize clearly the differences between what is called as native and non-native texts and also finding a solution for decreasing such lexico-grammatical differences between these two types of texts. In fact, this research aimed at exploring observable linguistic features at lexico-grammatical level, and evaluating them quantitatively to answer the following research questions:

1. Is there any significant difference between native and non-native abstracts in terms of transitivity (process types)?

2. Is there any significant difference between native and non-native abstracts in terms of lexical density? 
3. Is there any significant difference between native and non-native abstracts in terms of modality (adjunct)?

In order to solve the upcoming related problems, more effort is needed in the field of text analysis. If a researcher is about to write an academic article, s/he should forget about translation and the structure of the first language; instead, it is suggested to focus on the structure of the target language as more as possible. Sources of these problems will be found through analyzing transitivity, mood analysis, and lexical density based on Halliday' SFL model.

\section{MethodOLOGY}

Research design: This research has exploited a qualitative approach, analyzing the data through text analysis method.

Research material: The corpus of this research comprised 30 (15 native and 15 non-native) academic abstracts downloaded from two journals specialized in educational psychology. They were compared and contrasted in terms of lexical patterns. In order to have a text analysis with high precision, both categories were selected from the same discipline, within a time distance of 4 years.

Data collection procedure: As was stated above, educational psychology was used as discipline for downloading both native and non-native abstracts. The native abstracts were downloaded from the online Journal of Indigenous Research, Utah State University, (https://digitalcommons.usu.edu/kicjir/about.html). The focus of this publication is on research conducted with indigenous populations, with emphasis on psychology, education, and general health. students.

Non-native abstracts were taken from Educational Psychology (Educpsychol-UK), published by Taylor \& Francis (Routledge), which is also an online journal (www.bps.org.uk/publications/jEP_1.cfm). The theme of this international journal is inclusively related to research in psychology and education.

Thirty academic abstracts were chosen from the above journals in order to show the variations caused by stylistic tendency of these journals. In order to increase the reliability of the research, the regulated principles of sampling methods were applied in data collection, i.e. they were selected based on purposive sampling method to cover the expected discourse community, which is educational psychology in the present research.

Data analysis procedure: The selected data were analyzed manually and the numerical results were tabulated in the following tables. Besides, there are three more tables in the result section, Table 13 shows the lexical density and percentage of the native and non-native abstracts, Table 14 reveals mood analysis (types of adjuncts) in both native and non-native abstracts, and Table 15 depicts transitivity (different process types). Finally, based on the results of comparing each variable's percentages, the difference between dependent variables was measured.

TABLE 1.

SAMPle OF TeXT ANALYSIS OF A NON-NATIVE ABSTRACT, SENTENCE 1

\begin{tabular}{ll}
\hline Sentence 1 & The aim of this study was to investigate the interplay between test anxiety and working memory (WM) on \\
& mathematics performance in younger children. \\
\hline Transitivity & Relational Process (interplay between) \\
Modality & Circumstantial (younger children) \\
Lexical density & 12 out of 23 \\
\hline
\end{tabular}

TABLE 2.

SAMPLE OF TEXT ANALYSIS OF A NON-NATIVE ABSTRACT, SENTENCE 2

\begin{tabular}{ll}
\hline Sentence 2 & A sample of 624 grade 3 students completed a test battery consisting of a test anxiety scale, WM tasks and the \\
& Swedish national examination in mathematics for grade 3. \\
\hline Transitivity & Behavioral process (completed) \\
Modality & Adjunct: circumstantial (grade 3, Swedish) \\
Lexical density & 20 out of 29 \\
\hline
\end{tabular}

TABLE 3.

SAMPLE OF TEXT ANALySis OF A NON-NATIVE ABSTRACT, SENTENCE 3

\begin{tabular}{ll}
\hline Sentence 3 & The main effects of test anxiety and WM, and the two-way interaction between test anxiety and WM on \\
& mathematics performance, were modelled with structural equation modelling techniques. \\
\hline Transitivity & Behavioral process: modelled \\
& Relational process: interaction \\
Modality (adjunct) & Existential adjuncts: --------- \\
Lexical density & 17 out of 27 \\
\hline
\end{tabular}

TABLE 4.

SAMPLE OF TEXT ANALYSIS OF A NON-NATIVE ABSTRACT, SENTENCE 4

\begin{tabular}{ll}
\hline Sentence 4 & $\begin{array}{l}\text { Additionally, the effects were also tested separately on tasks with high WM demands (mathematical problem- } \\
\text { solving) versus low WM demands (basic arithmetic). As expected, WM positively predicted mathematics } \\
\text { performance in all three models (overall mathematics performance, problem-solving tasks, and basic arithmetic). }\end{array}$ \\
\hline Transitivity & Behavioral process: tested \\
& Mental process: predicted \\
Modality (adjunct) & Adjunct: conjunctive: Additionally \\
& adjunct: circumstantial: positively predicted \\
& adjunct: circumstantial: versus \\
Lexical density & $(32$ out of 40$)$
\end{tabular}


TABLE 5.

SAMPle of TeXt ANALYSis OF A NON-NATIVE ABStRaCt, SENTENCE 5

\begin{tabular}{|c|c|}
\hline Sentence 5 & $\begin{array}{l}\text { Test anxiety had a negative effect on problem-solving on the whole sample level but concerning basic } \\
\text { arithmetic only students with lower WM were affected by the negative effects of test anxiety on performance. }\end{array}$ \\
\hline Transitivity & $\begin{array}{l}\text { Existential process: } \text { had } \\
\text { negative adjunct: circumstantial: } \text { negative effects }\end{array}$ \\
\hline Modality (adjunct) & $\begin{array}{l}\text { adjunct: conjunctive: } \text { but } \\
\text { adjunct: circumstantial: } \text { negative effects }\end{array}$ \\
\hline Lexical density & (21 out of 33) \\
\hline & $\begin{array}{c}\text { TABLE } 6 . \\
\text { SAMPLE OF TEXT ANALYSIS OF A NON-NATIVE ABSTRACT, SENTENCE } 6\end{array}$ \\
\hline Sentence 6 & $\begin{array}{l}\text { Thus, students with low WM are more vulnerable to the negative effects of test anxiety in low WM tasks like } \\
\text { basic arithmetic. }\end{array}$ \\
\hline Transitivity & $\begin{array}{l}\text { Existential process: are } \\
\text { adjunct: conjunctive: } \text { thus }\end{array}$ \\
\hline Modality (adjunct) & \\
\hline Lexical density & $(14$ out of 22$)$ \\
\hline & $\begin{array}{l}\text { TABLE } 7 . \\
\text { SAMPLE OF TEXT ANALYSIS OF A NON-NATIVE ABSTRACT, SENTENCE } 7\end{array}$ \\
\hline Sentence 7 & The results are discussed in relation to the early identification of test anxiety. \\
\hline Transitivity & $\begin{array}{l}\text { Verbal process: discussed } \\
\text { Relational process: in relation to }\end{array}$ \\
\hline Modality & - \\
\hline Lexical density & (7 out of 13) \\
\hline
\end{tabular}

TABLE 8.

SAmple of TeXt ANalysis OF a Native AbStRact, SENTENCE 1

\begin{tabular}{ll}
\hline Sentence 1 & $\begin{array}{l}\text { Teaching Indigenous students environmental education through an interdisciplinary learning approach takes } \\
\text { advantage of a more holistic perspective that these students share. }\end{array}$ \\
\hline Transitivity & $\begin{array}{l}\text { Behavioral process: teaching } \\
\text { adjunct: circumstantial: } \text { more holistic perspective } \\
\text { adjunct: conjunctive: } \text { through } \\
\text { Modality (adjunct) }\end{array}$ \\
Lexical density & (13 Out of 21)
\end{tabular}

TABLE 9.

SAmple of TeXt ANAlysis OF a NATIVE ABSTRACT, SENTENCE 2

\begin{tabular}{|c|c|}
\hline Sentence 2 & $\begin{array}{l}\text { Students enrolled in three different Native American and Indigenous Studies courses were asked to } \\
\text { contribute to a class capstone project. }\end{array}$ \\
\hline $\begin{array}{l}\text { Transitivity } \\
\text { Modality (adjunct) } \\
\text { Lexical density }\end{array}$ & $\begin{array}{l}\text { Verbal process: were asked } \\
\text { Behavioral process: contribute } \\
\text { adjunct: circumstantial: Native American and Indigenous Studies } \\
\text { (14 out of } 20)\end{array}$ \\
\hline & $\begin{array}{c}\text { TABLE } 10 . \\
\text { SAMPLE OF TEXT ANALYSIS OF A NATIVE ABSTRACT, SENTENCE } 3\end{array}$ \\
\hline Sentence 3 & $\begin{array}{l}\text { The three projects consisted of a land acquisition and management proposal with the Miami Nation of } \\
\text { Indiana, a proposal for a forest management plan for the Keeweenaw Bay Indian Community, and } \\
\text { environmental histories of the Miami, Potawatomi, and Shawnee in Indiana. }\end{array}$ \\
\hline $\begin{array}{l}\text { Transitivity } \\
\text { Modality (adjunct) } \\
\text { Lexical density }\end{array}$ & $\begin{array}{l}\text { Existential process: consisted of } \\
\text { adjunct: circumstantial: Miami Nation of Indiana } \\
\text { (23 out of } 41)\end{array}$ \\
\hline & $\begin{array}{c}\text { TABLE } 11 . \\
\text { SAMPLE OF TEXT ANALYSIS OF A NATIVE ABSTRACT, SENTENCE } 4\end{array}$ \\
\hline Sentence 4 & $\begin{array}{l}\text { The development of these service and community projects in natural resource management and environmental } \\
\text { studies promoted an interdisciplinary teaching method because students had multiple considerations before, } \\
\text { during, and after the creation of the assigned tasks. }\end{array}$ \\
\hline Transitivity & Behavioral process: promoted \\
\hline Modality (adjunct) & $\begin{array}{l}\text { Conjunctive adjunct: } \text { because } \\
\text { Circumstantial adjunct: } \text { interdisciplinary teaching } \text { method } \\
\text { Mood adjunct: } \text { before, during, and after }\end{array}$ \\
\hline
\end{tabular}

TABLE 12.

SAMPle of TeXt ANAlysis OF A NATIVE ABStRact, SENTENCE 5

\begin{tabular}{ll}
\hline Sentence 5 & $\begin{array}{l}\text { These projects were designed to build capacity with students enrolled in the courses and to promote tribal } \\
\text { sovereignty. }\end{array}$ \\
\hline Transitivity & Mental process: were designed \\
Modality (adjunct) & --- - $^{---}$ \\
Lexical density & (10 out of 18$)$ \\
\hline
\end{tabular}




\section{RESULTS AND ANALYSIS}

After downloading the articles and counting the number of their lexical density, adjuncts including conjunctive and circumstantial, and process types including material, mental, relational, verbal, behavioral, and existential, the following results were obtained which is considerable in three

TABLE 13.

LeXICAL DENSITY AND PERCENTAGE OF NATIVE AND NON-NATIVE ABSTRACTS

\begin{tabular}{lll}
\hline & Lexical density & Percentage \\
\hline Non-native & 1461 out of 2466 & $59.91 \%$ \\
Native & 1281 out of 2145 & $59.72 \%$ \\
\hline
\end{tabular}

As it is depicted in Table 13, from among the selected abstracts, results of lexical density of 30 native and non-native abstracts and their percentages are shown. Accordingly, lexical density of nan-native abstracts, from among 2466 words, is 1461 and lexical density of native abstracts, from among 2145 words, is 1281. As a result, total percentage of nonnative and native abstracts are $59.91 \%$ and $59.72 \%$ respectively.

TABLE 14. AdJUNCTS' SUBCATEGORIES FREQUENCY OF NATIVE AND NON-NATIVE ABSTRACTS

\begin{tabular}{lllll} 
& \multicolumn{2}{c}{ ADJUNCTS } & ConCATEGORIES FREQUENCY OF NATIVE AND NON-NATIVE ABSTRACTS \\
\hline Non-native & Conjunctive frequency & Circumstantial frequency & Vocative frequency & Modal frequency \\
Native & 54 & 96 & 0 & 0 \\
\hline
\end{tabular}

According to Table 14, mood analysis (adjuncts) divided into four two types including modal, vocative, conjunctive and circumstantial that the results of the third and fourth ones in non-native abstracts were 54 and 96 respectively. The same results for native abstracts were 39 and 93 respectively. Adding this issue is important that the modal and vocative did not have any example in such academic abstracts, this is why their frequency is 0 .

TABLE 15.

FREQUENCY OF TRANSITIVITY'S SUBCATEGORIES OF THE NATIVE AND NON-NATIVE ABSTRACTS

\begin{tabular}{llllllll}
\hline & Material & Mental & Relational & Verbal & Behavioral & Existential & Sum \\
\hline Non-native & 3 & 23 & 7 & 36 & 24 & 15 \\
Native & 12 & 13 & 6 & 19 & 15 & 108 \\
\hline
\end{tabular}

As it is depicted in Table 15, transitivity divided into 6 process types including material, mental, relational, verbal, behavioral, and existential processes. Total number of transitivity items are 108 in non-natives and 80 in natives. Separate results for material, mental, relational, verbal, behavioral, and existential processes in non-native abstracts were $3,23,7,36,24$, and 15 respectively. Obviously, verbal process type was the most frequent one and material process type had the least frequency. Also, the results in native abstracts were 12,13, 6, 19, 15, and 15 respectively. As it is considerable in this table, verbal process type was the most frequent one which was almost half of the ones in nonnative process types and existential process type had the least frequency. On the contrary of the mental processes in non-native abstracts and the existential processes in native ones, both native and non-native ones used equal verbal and behavioral processes; however, verbal, mental, and behavioral process types were the most common processes.

\section{DISCUSSION}

The percentage of lexical density in native and non-native abstracts was $59.91 \%$ and 59/72\% respectively. Therefore, there was not any significant difference between the native and non-native abstracts in terms of lexical density. From among different methods of measuring lexical density, Halliday's (1989) method was used in this research. In fact, the number of lexical words in a clause as lexical density was taken into consideration by him. Based on Halliday, if the values for lexical density are higher than 10, texts even become difficult to read (Valipour et al., 2016): However, chisquares result of Valipour et al. (2016) analysis for each discipline regarding the transitivity and mood depicted that there are significant differences between papers over time at .05 level of significance $(.000<.05)$, therefore their results in terms of mood analysis (adjuncts) are in line with the results of the present research, but regarding transitivity is not in-line with the results of the present research.

Regarding another article carried out by Huen (2011) which was about spoken augural addresses of America's Presidents, Bush and Obama, lexico-grammatical analysis has shown the application of some of the transitivity structures with stable process type, which is in line with the results of the present research in terms of transitivity.

Choice of words is, actually, meaningful in the principle of functional grammar. Functions of the word and also its meaning by the choice of the words were under focus in this principle. (Ye, 2010). In comparison with non-native abstracts, lexical density in the native abstracts was not based on the Halliday's standards. Also, lexical density in the non-native abstracts was not quite close to Halliday's theory, but the length of the sentences in non-native abstracts was shorter than the native ones.

The analyzed abstracts were informative and most of their clauses and sentences were structured based on declarative mood indicated that the communicated information is very strong and factual-based. This mood type strengthens the 
text's appeal to the readers/listeners (Noor, Ali, Muhabat, \& Kazemian, 2015). Mood analysis of native and non-native abstracts showed that the native sentences were grammatically structured based on the standards. in such kind of the text, this is what one would expect that accordingly interrogatives or imperatives would be super unusual (Banks, 2002). Also, mood analysis of non-native abstracts depicted that the mentioned regulations and principles of grammatical structures were not considered as existed in native abstracts. Analyzing the types of adjuncts showed that non-natives used mood, conjunctive and modal adjuncts. This premise in native abstracts is evident too, except the fact that the level of using conjunctive adjunct was different. Native abstracts were well-organized in a way that they did not require considerable conjunctive adjuncts to connect to different parts. Therefore, both native and non-native abstracts were used at the same level of mood and circumstantial adjuncts, but the frequency of using conjunctive adjunct in the nonnatives were significantly higher than the natives (54 and 39). The frequency of circumstantial adjunct used in both native and non-native abstracts showed that there is a kind of tendency toward the elicitation of the issues in educational psychology through the extended use of the circumstantial adjunct. Although using this type of adjunct caused the sentences to be lengthy in both native and non-native abstracts, it makes the meaning more explicit.

The transitivity analysis of process types indicated that the most frequent process type used in the native abstracts were verbal, behavioral, and existential, but in non-native abstracts the most frequent process types were verbal, behavioral, and mental. These two types are having a minor, but close relationship with each other that will be considered by some commentators, or even see verbal process as a sub-group of mental process (Berry \& Matthiessen, 1996). The rare use of material process in both native and non-native abstracts showed the weak relationship between the notions and entities (Banks, 2002). The distribution frequency of the processes in Table 15 has shown that after the verbal and behavioral processes, the mental process in non-native abstracts and existential process in native abstracts enjoyed the highest level. In comparison with technical texts that material process was the most commonly-used element in their texts, transitivity analysis of psychological texts has shown that the verbal, mental and behavioral processes were the most frequently-used processes.

\section{CONCLUSION}

The present research is actually an extension to the similar research conducted by previous researchers, and provides an adequate starting point for the EFL learners owing to its practical nature. The findings of this study have implications for novice writers who would like to present their writings in academic settings. They further reveal that Halliday's SFL model can be an acceptable and effective model for language analysis of religious texts. The presentation of the tabulated forms is also very helpful for the beginners. The findings can, in fact, be exploited by such extended groups as journal editors, teachers and students. They can help them improve their writing in a right, accurate and academic mode. A final word is that based on the findings of this research, through gaining standard and high quality writing, nonnatives can boost their chance to publish their articles in journals with high impact factors.

\section{REFERENCES}

[1] Almurashi, W. A. (2016). An introduction to Halliday's systemic functional linguistics. Journal for the study of English Linguistics, 4(1), 70-80.

[2] Arancón, P. R. (2013). The use of SFL genre theory for the analysis of students' writing skills in ESP. Revista española de lingüística aplicada, (1), 245-262.

[3] Banks, D. (2002). Systemic Functional Linguistics as a model for text analysis. ASp. la revue du GERAS, (35-36), 23-34.

[4] Berry, H. M., \& Matthiessen, C. (1996). An introduction to systemic linguistics: Structures and systems (Vol. 1): BT Batsford Limited.

[5] Eggins, S. (2004). Introduction to systemic functional linguistics: London, U K: Continuum.

[6] Halliday, M.A.K. (1975) Learning

[7] Gledhill, C. (2009). Colligation and the cohesive function of present and past tense in the scientific research article. Les Temps et les textes de spécialité. Paris: L'Harmattan, 65-84.

[8] Halliday, M. A. K. (1994). An introduction to functional grammar ( $2^{\text {nd }}$ ed.). London: Edward Arnold.

[9] Halliday, M. A. K., \& Matthiessen, C. M. (2004). Halliday's introduction to functional grammar (3 ed.). London: Edward.

[10] Halliday, M. A. K., \& Webster, J. J. (2009). Continuum companion to systemic functional linguistics: London: Continuum Books.

[11] Holtz, M. (2011). Lexico-grammatical properties of abstracts and research articles. A corpus-based study of scientific discourse from multiple disciplines. Technische Universität.

[12] Huen, K. L. B. (2011). Text analysis with a systemic functional approach: Analyzing US presidential inaugural address. Retrieved from City University of Hong Kong, CityU Institutional Repository.

[13] Martin, J. R. (1984). Language, register and genre. In F. Christie (Ed.), Language Studies: Children's Writing: Reader (pp. 1021). Geelong, Victoria: Deakin University Press.

[14] Martin, J. R. (1997). Analyzing genre: functional parameters. In F. Christie (Ed.), Genre and Institutions: Social Processes in the Workplace and School (pp. 3-39). London and Washington: Cassell.to Cognition. London/New York: Continuum.

[15] Martin, J. R., Matthiessen, C., \& Painter, C. (1997). Working with functional grammar. London: Edward Arnold.

[16] Noor, M., Ali, M., Muhabat, F., \& Kazemian, B. (2015). Systemic Functional Linguistics Mood Analysis of the Last Address of the Holy Prophet (PBUH). International Journal of Language and Linguistics. Special Issue: Critical Discourse Analysis, Rhetoric, and Grammatical Metaphor in Political and Advertisement Discourses, 3(5-1), 1-9. 
[17] Norouzi, M. H., Farahani, A. A. K., \& Farahani, D. B. (2012). Deverbal Nominalisations across written-spoken dichotomy in the language of science. Theory and Practice in Language Studies, 2(11), 2251-2261.

[18] O'Donnell, M. (2011). Introduction to systemic functional linguistics for discourse analysis. Language, Function and Cognition, 1-18.

[19] Paltridge, B. (2012). Discourse analysis: An introduction. London: Bloomsbury Publishing.

[20] Praxedes Filho, P. H. (2004). Systemic functional grammar: a tool to investigate the lexicogrammatical complexification of advanced portuguese-efl interlanguage. Ilha do Desterro A Journal of English Language, Literatures in English and Cultural Studies(46), 211-252.

[21] Stubbs, M. (2004). Computer-assisted studies of language and culture. Text and corpus analysis, 1-15.

[22] Teich, E., Janich, N., \& Holtz, M. (2011). Lexico-grammatical properties of abstracts and research articles. A corpus-based study of scientific discourse from multiple disciplines. Technische Universität.

[23] Thompson, G. (1996). Introducing functional grammar. Londen: Edward Arnold.

[24] Thompson, G. (2004). Introducing functional grammar ( $2^{\text {nd }}$ ed.). London: Oxford University Press.

[25] To, V., Fan, S., \& Thomas, D. (2013). Lexical density and readability: A case study of English textbooks. Internet Journal of Language, Culture and Society, (37), 61-71.

[26] Valipour, V., Aidinlu, N. A., \& Asl, H. D. (2016). Investigating lexico-grammaticality in academic abstracts and their full research papers from a diachronic perspective. The Journal of Applied Linguistics, 9(19): 178-197.

[27] White, P. R. R. (2000). Functional grammar. Birmingham: University of Birmingham.

[28] Young, L., \& Harrison, C. (2004). Systemic functional linguistics and critical discourse analysis: Studies in social change: A\&C Black.

[29] Yuli, S., \& Yushan, Z. (2012). A comparison of transitivity system in English and Chinese. Cross-Cultural Communication, $8(4), 75-90$

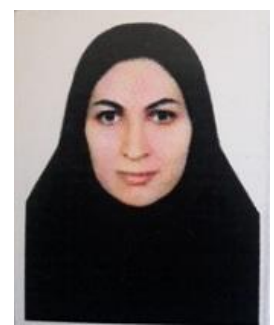

Massome Raeisi, Department of English, Isfahan (Shareza) Branch, Islamic Azad University, Isfahan, Iran.

Massome has just finished her master from IAUSH majoring Translation Studies. She is now working on two articles in the field of translation studies and teaching. She translated a book entitled: An Introduction to Polymer compounding (two volumes) which is going to publish in Islamic Azad University of Shahreza Publication.

Ms. Raeisi's field of interest is virtual reality (VR) and the usage of technology in teaching

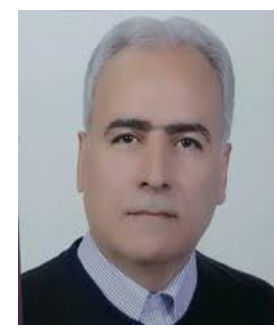

Hossein Vahid Dastjerdi is associate professor of applied linguistics and has taught courses of variegated character, including translation courses. He has been a fellow of the English Centers at the universities of Isfahan and Shiraz where he has investigated into issues related to materials preparation for GE. and ESP. courses. He is the author of a number of books in this respect. He has also published a good number of articles on discourse, testing and translation in local and international journals. He is Editor-in-Chief of International Journal of Foreign Language Teaching and Research and member of editorial board of some Iranian and nonIranian journals. Dr. Vahid's current research interests include testing, materials development, metaphoricity of language, discourse analysis, pragmatics and critical discourse analysis.

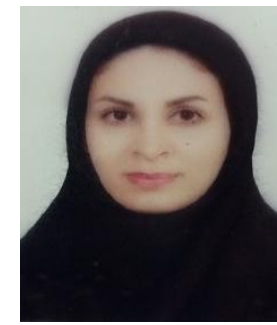

Mina Raeisi, Lecturer, Department of English, Isfahan (Khorasgan) Branch, Islamic Azad University, Isfahan, Iran

Mina holds Master's degree in English translation from Islamic Azad University of Isfahan (Khorasgan) Branch. She is the lecturer of IAUKB and has been taught a variety of courses including English translation, specialized English of different majors there, from 2013 to 2019 and commenced teaching IELTS in 2018. She has cooperated with IAUKH English Department to hold RTETL Conference on 2013 and work as the executive director of RELP Journal, from 2013 to 2017. She has published in the areas of bilingualism, selfdirected learning, teaching translation, and text analysis and authored or translated five books. Her latest book published on 2018, Handbook of Energy Audits.

Ms. Raeisi is interested in teacher education, using different types of technology to improve teaching quality, NEST and NNEST, and also social justice are among her field of interest 